\title{
Three-dimensional ultrasonography and power Doppler for discrimination between benign and malignant endometrium in premenopausal women with abnormal uterine bleeding
}

\author{
Mohamed El-Sharkawy *, Akmal El-Mazny, Wafaa Ramadan, Dina Hatem, Aly Abdel-Hafiz, Mohamed Hammam
} and Adel Nada

\begin{abstract}
Background: Ultrasonography has been extensively used in women suspected of having a gynecological malignancy. The aim of this study is to evaluate the efficacy of 3D ultrasonography and power Doppler for discrimination between benign and malignant endometrium in premenopausal women with abnormal uterine bleeding.

Methods: This cross-sectional study included 78 premenopausal women with abnormal uterine bleeding scheduled for hysteroscopy and endometrial curettage. The endometrial thickness (ET), uterine artery pulsatility index (PI) and resistance index (RI), and endometrial volume (EV) and 3D power Doppler vascularization index (VI), flow index (FI), and vascularization flow index (VFI) were measured and compared with hysteroscopic and histopathologic findings.
\end{abstract}

Results: The ET $(P<0.001)$, EV $(P<0.001)$, and endometrial VI $(P<0.001)$ and VFI $(P=0.043)$ were significantly increased in patients with atypical endometrial hyperplasia and endometrial carcinoma $(n=10)$ than those with benign endometrium $(n=68)$; whereas, the uterine artery PI and Rl and endometrial FI were not significantly different between the two groups. The best marker for discrimination between benign and malignant endometrium was the $\mathrm{VI}$ with an area under the ROC curve of 0.88 at a cutoff value of $0.81 \%$.

Conclusion: 3D ultrasonography and power Doppler, especially endometrial VI, may be useful for discrimination between benign and malignant endometrium in premenopausal women with abnormal uterine bleeding.

Keywords: 3D ultrasonography, Doppler, Endometrial carcinoma, Hysteroscopy, Premenopausal bleeding

\section{Background}

Endometrial carcinoma is the most common form of gynecologic cancer in developed countries, and it is the fourth most common malignant tumor among women worldwide [1]. Abnormal uterine bleeding is usually the first symptom; therefore, appropriate evaluation of women with premenopausal or postmenopausal bleeding will allow for early diagnosis of endometrial carcinoma and the best opportunity for cure [2].

\footnotetext{
* Correspondence: kingdoc82@outlook.com
Department of Obstetrics and Gynecology, Faculty of Medicine, Cairo
University, Cairo, Egypt

*Correspondence: kingdoc82@outlook.com
Department of Obstetrics and Gynecology, Faculty of Medicine, Cairo
University, Cairo, Egypt

*Correspondence: kingdoc82@outlook.com
Department of Obstetrics and Gynecology, Faculty of Medicine, Cairo
University, Cairo, Egypt
}

(0) 2016 El-Sharkawy et al. Open Access This article is distributed under the terms of the Creative Commons Attribution 4.0 International License (http://creativecommons.org/licenses/by/4.0/, which permits unrestricted use, distribution, and reproduction in any medium, provided you give appropriate credit to the original author(s) and the source, provide a link to the Creative Commons license, and indicate if changes were made. The Creative Commons Public Domain Dedication waiver (http://creativecommons.org/publicdomain/zero/1.0/) applies to the data made available in this article, unless otherwise stated. suspected of having a gynecological malignancy, especially in ovarian [3] and endometrial [4] cancer. In fact, transvaginal ultrasonography is considered the initial imaging procedure for evaluating abnormal vaginal bleeding due to its ability to depict endometrial pathology, its widespread availability, and its excellent safety profile and cost effectiveness [5].

Three-dimensional ultrasonography is a new imaging technique that has become currently available in gynecologic practice [6], specifically in gynecologic oncology [7]. In addition, 3D power-Doppler ultrasonography allows a $3 \mathrm{D}$ reconstruction of the vascular network and also 
calculating vascular indices based on the total and relative amount of power Doppler information within the volume of interest [8].

The aim of this study is to evaluate the efficacy of 3D ultrasonography and power Doppler for discrimination between benign and malignant endometrium in premenopausal women with abnormal uterine bleeding.

\section{Methods}

This cross-sectional study was conducted at the Department of Obstetrics and Gynecology, Faculty of Medicine, Cairo University, during the period from August 2013 to May 2014. The study protocol was approved by the Research Ethics Committee, and informed verbal consent was obtained from all participants.

The study population consisted of 78 premenopausal women with abnormal uterine bleeding scheduled for hysteroscopy and endometrial curettage. They were subjected to detailed history taking, complete general and gynecological examination, routine pre-operative laboratory investigations, and preliminary transvaginal ultrasound. The exclusion criteria included uterine fibroids, adenomyosis, endometrial polyps, and any general diseases, hormones or medications that could potentially affect pelvic blood flow.

Transvaginal ultrasound (Voluson 730; Kretz, Zipf, Austria) examinations were performed within $24 \mathrm{~h}$ prior to surgery. Using ultrasound in the 2D mode, the endometrial thickness (ET) was measured as the thickest part (double layer) in the sagittal plane (Fig. 1). Then, color Doppler was activated and the flow velocity waveforms were obtained from the ascending main branch of the uterine artery on both sides of the internal os (Fig. 2). Three similar consecutive waveforms of good quality were analyzed, and the averaged right and left uterine artery pulsatility index (PI) and resistance index (RI) were calculated.

The ultrasound was then switched to the 3D mode with power Doppler. The setting conditions for this study were standardized using a frequency at 3-9 MHz, pulse repetition frequency at $0.6 \mathrm{kHz}$, gain at -4.0 , and wall motion filter at low 1 . The Virtual Organ Computer-Aided Analysis $\left(\mathrm{VOCAL}^{\mathrm{rm}}\right)$ Imaging Program for the 3D power Doppler histogram analysis was used to measure the endometrial volume (EV) and 3D power Doppler indices within the endometrium (Figs. 3 and 4).

Vascularization index (VI) measures the ratio of the number of color voxels to the total number of voxels (\%) and represents the presence of blood vessels (vascularity). Flow index (FI) measures the mean power Doppler signal intensity (0-100) and represents the average intensity of blood flow. Vascularization flow index (VFI) is calculated by multiplying VI and FI (0-100) and represents a combination of vascularity and flow intensity.

Hysteroscopic examination was performed routinely before endometrial curettage using a rigid $30^{\circ}$ hysteroscope and a 4-mm-diameter diagnostic sheath (Karl Storz GmbH \& Co KG, Tuttlingen, Germany). The hysteroscopic diagnosis was based on the following criteria: atrophic endometrium-thin and homogeneous in appearance; endometrial hyperplasia-thickened endometrium, easily indented with pressure, with or without multipolyp appearance; and endometrial carcinoma-irregular growth with or without abnormal vascularization.

Endometrial sampling was carried out by formal dilatation and curettage. The histopathological samples were examined by two senior pathologists who determined

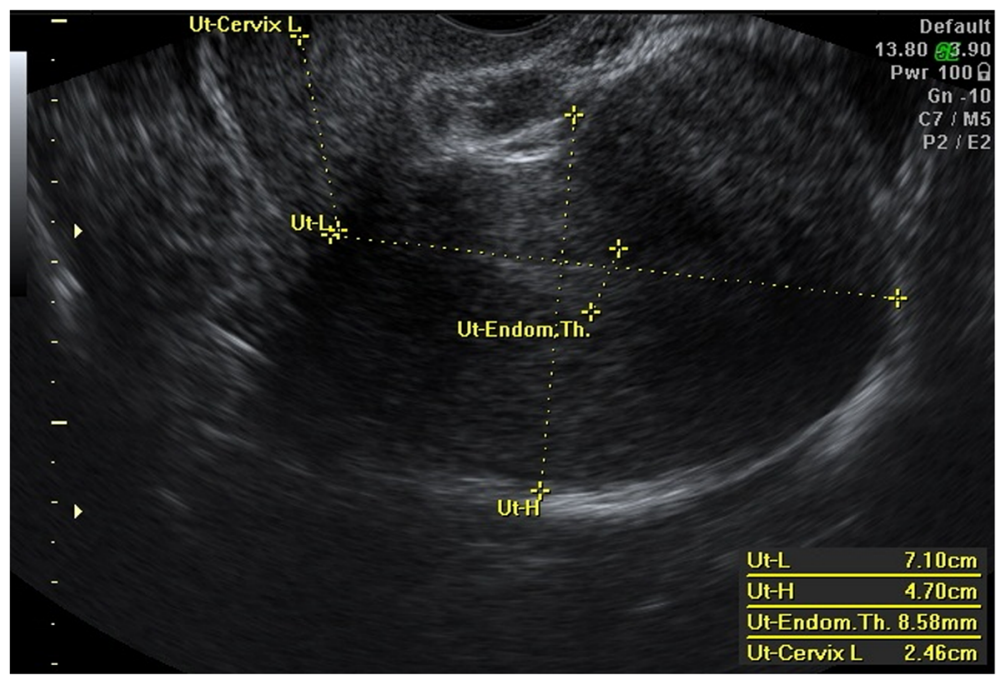

Fig. 1 Two-dimensional ultrasound measurement of endometrial thickness 


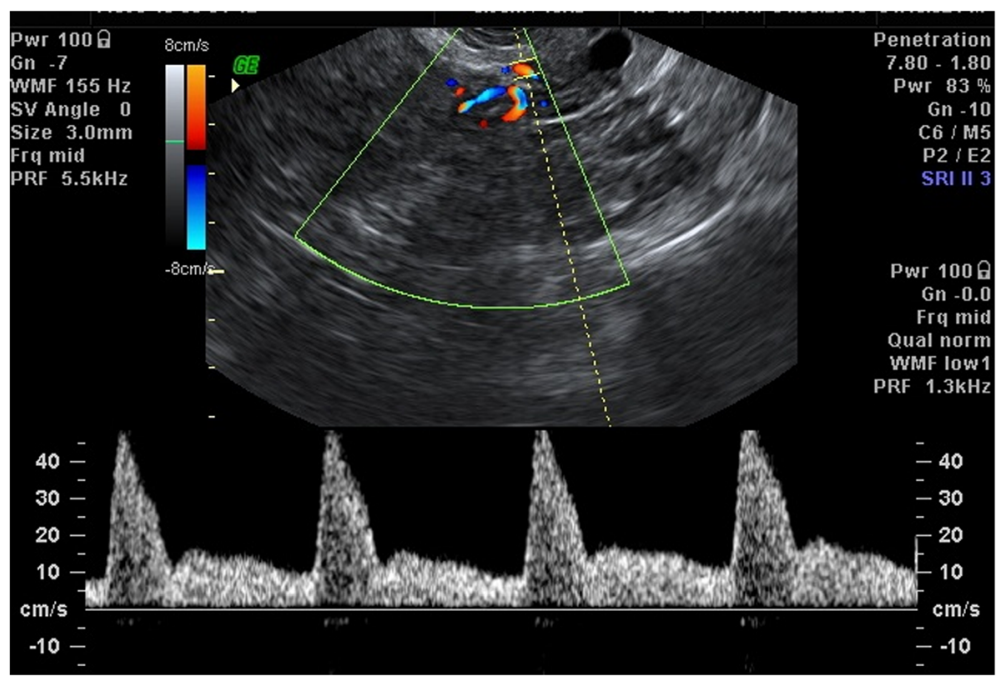

Fig. 2 Two-dimensional color Doppler of uterine artery flow velocity waveforms

the final diagnosis. Ultrasonographic findings were compared with hysteroscopic and histopathologic findings.

\section{Statistical analysis}

Data were expressed as mean \pm SD or $n$ (\%) unless otherwise indicated. Continuous data were compared using Student $t$ test or Mann-Whitney $U$ test, as appropriate. Receiver-operating characteristic (ROC) curve analysis was used to evaluate the optimal cutoff value of ultrasound markers for prediction of malignant endometrial lesions; based on an equivalent sensitivity and specificity, and the highest value of the area under the curve (AUC). A $P$ value $<0.05$ was considered statistically significant. The Statistical Package for the Social Science
(SPSS Inc., Chicago, IL, USA), version 16.0, was used for data analyses.

Sample size calculation reveals that with a margin of error of $4.99 \%$ and a response distribution of $50 \%$, the confidence level was $52 \%$; whereas with a margin of error of $9.92 \%$ and a response distribution of $50 \%$, the confidence level was $84 \%$.

\section{Results}

Patients' characteristics and histopathological diagnosis are shown in Table 1. Of the 78 women included in the study, 68 (87\%) had benign endometrium and 10 (13\%) had malignant endometrium (atypical hyperplasia and carcinoma). Hysteroscopic and histopathologic findings were in agreement in almost all cases.

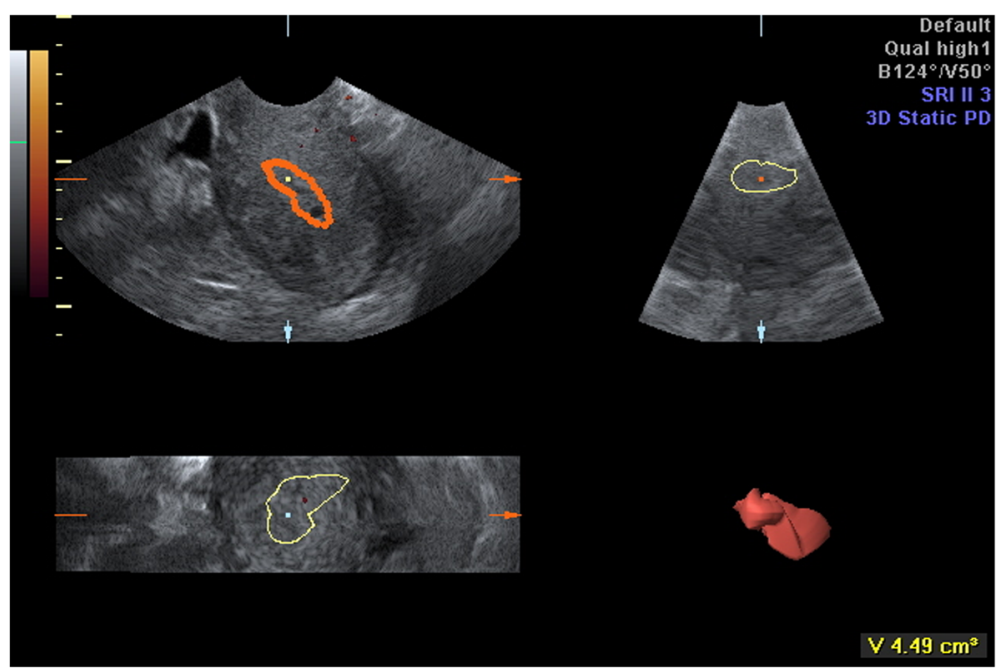

Fig. 3 Virtual Organ Computer-Aided Analysis of the endometrium 


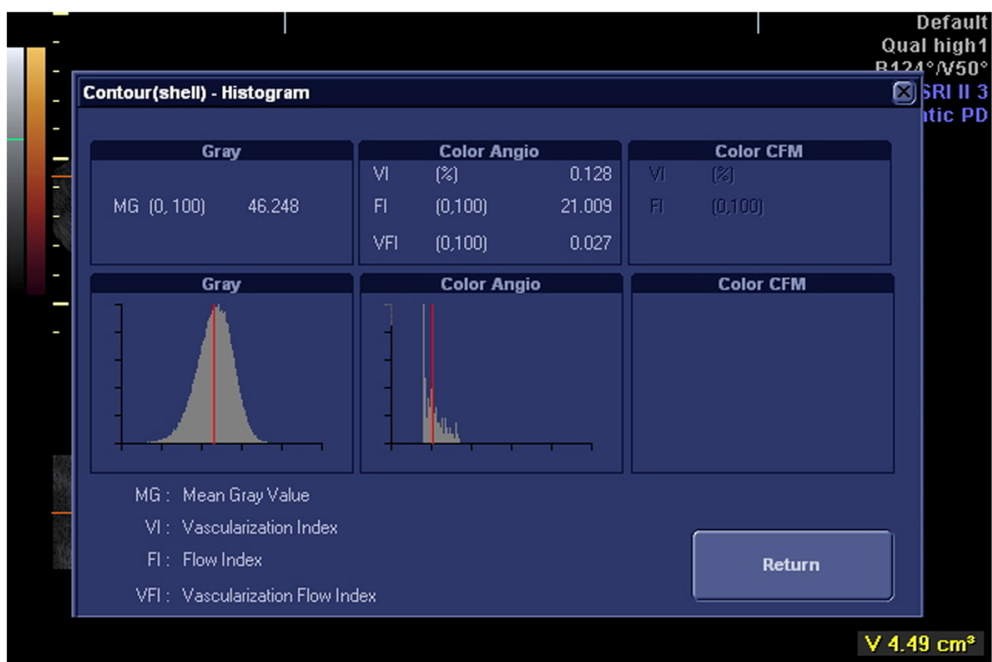

Fig. 4 Three-dimensional power Doppler flow indices of the endometrium

The age was significantly higher $(P=0.032)$ in patients with malignant endometrium; however, there were no significant differences in the parity $(P=0.954)$, weight $(P=$ $0.952)$, height $(P=0.244)$, or body mass index $(P=0.248)$ between the two groups. The ET $(P<0.001)$, EV $(P<0.001)$, and endometrial VI $(P<0.001)$ and VFI $(P=0.043)$ were significantly increased in patients with malignant endometrium; whereas, the uterine artery PI $(P=0.296)$ and RI $(P=0.922)$ and endometrial FI $(P=0.474)$ were not significantly different between the two groups (Table 2).

The diagnostic performance of the various ultrasound markers is shown in Table 3. The best marker for discrimination between benign and malignant endometrium was the VI with an AUC of 0.88 at a cutoff value of $0.81 \%$. The sensitivity, specificity, positive predictive value (PPV), negative predictive value (NPV), likelihood

Table 1 Patients' characteristics and histopathological diagnosis $(n=78)$

\begin{tabular}{ll}
\hline Characteristic & Value \\
\hline Age $(\mathrm{y})$ & $47.46 \pm 2.94$ \\
Parity & $4.18 \pm 1.18$ \\
Weight $(\mathrm{kg})$ & $87.79 \pm 11.49$ \\
Height $(\mathrm{cm})$ & $157.10 \pm 5.50$ \\
BMI $\left(\mathrm{kg} / \mathrm{m}^{2}\right)$ & $35.53 \pm 2.09$ \\
Endometrial histopathology; $(\%)$ & \\
Normal endometrium & $20(25.64)$ \\
Simple hyperplasia & $25(32.05)$ \\
Distorted proliferative & $16(20.51)$ \\
Atrophic endometrium & $7(8.97)$ \\
Atypical hyperplasia & $4(5.13)$ \\
Adenocarcinoma & $6(7.69)$ \\
\hline
\end{tabular}

BMI body mass index ratio of a positive test (LR+), and likelihood ratio of a negative test (LR-) for endometrial VI at $0.81 \%$ (90\%, $88 \%, 53 \%, 98 \%, 7.50$, and 0.11 , respectively) were higher than those for ET at $19 \mathrm{~mm}(80 \%, 72 \%, 30 \%$, $96 \%, 2.86$, and 0.28 , respectively), EV at $8 \mathrm{~cm}^{3}$ (90\%, $79 \%, 39 \%, 98 \%, 4.29$, and 0.13 , respectively) and endometrial VFI at $0.22(60 \%, 68 \%, 23 \%, 92 \%, 1.88$, and 0.59 , respectively).

\section{Discussion}

To the best of our knowledge and review of literature, this is the first study to evaluate the efficacy of 3D ultrasonography and power Doppler for discrimination between benign and malignant endometrium in women

Table 2 Characteristics of patients with benign and malignant endometrium

\begin{tabular}{lccc}
\hline Characteristic & Benign $(n=68)$ & Malignant $(n=10)$ & $P$ value \\
\hline Age $(\mathrm{y})$ & $46.88 \pm 1.95$ & $48.43 \pm 2.99$ & $0.032^{\mathrm{a}}$ \\
Parity & $4.18 \pm 1.21$ & $4.20 \pm 1.03$ & 0.954 \\
Weight $(\mathrm{kg})$ & $87.76 \pm 10.74$ & $88.00 \pm 16.44$ & 0.952 \\
Height $(\mathrm{cm})$ & $157.38 \pm 5.80$ & $155.20 \pm 1.81$ & 0.244 \\
BMI $\left(\mathrm{kg} / \mathrm{m}^{2}\right)$ & $35.29 \pm 1.84$ & $36.62 \pm 8.42$ & 0.248 \\
ET (mm) & $7.615 \pm 5.493$ & $21.400 \pm 9.489$ & $<0.001^{\mathrm{a}}$ \\
Uterine artery PI & $1.847 \pm 0.638$ & $2.080 \pm 0.755$ & 0.296 \\
Uterine artery RI & $1.140 \pm 1.583$ & $1.190 \pm 0.796$ & 0.922 \\
EV (cm ${ }^{3}$ ) & $3.410 \pm 2.728$ & $7.534 \pm 3.622$ & $<0.001^{\mathrm{a}}$ \\
Endometrial VI (\%) & $0.310 \pm 0.418$ & $1.005 \pm 0.597$ & $<0.001^{\mathrm{a}}$ \\
Endometrial FI (0-100) & $22.897 \pm 4.547$ & $24.212 \pm 9.562$ & 0.474 \\
Endometrial VFI (0-100) & $0.100 \pm 0.157$ & $0.204 \pm 0.072$ & $0.043^{\mathrm{a}}$
\end{tabular}

$B M I$ body mass index, $E T$ endometrial thickness, $P I$ pulsatility index,

$R I$ resistance index, EV endometrial volume, $F I$ flow index, VI vascularization index, $V F I$ vascularization flow index

${ }^{\text {a }}$ Statistically significant 
Table 3 Diagnostic performance of ultrasound markers

\begin{tabular}{lllll}
\hline Parameter & ET & EV & Endometrial VI & Endometrial VFI \\
\hline Cutoff value & $19 \mathrm{~mm}$ & $8 \mathrm{~cm}^{3}$ & $0.81 \%$ & 0.22 \\
AUC & 0.73 & 0.81 & 0.88 & 0.67 \\
Sensitivity (\%) & 80 & 90 & 90 & 60 \\
Specificity (\%) & 72 & 79 & 88 & 68 \\
PPV (\%) & 30 & 39 & 53 & 23 \\
NPV (\%) & 96 & 98 & 98 & 92 \\
LR+ & 2.86 & 4.29 & 7.50 & 1.88 \\
LR- & 0.28 & 0.13 & 0.11 & 0.59 \\
\hline
\end{tabular}

$E T$ endometrial thickness, $E V$ endometrial volume, $V I$ vascularization index, $V F I$ vascularization flow index, $A U C$ area under receiver-operating characteristics (ROC) curve, PPV positive predictive value, NPV negative predictive value, $L R+$ likelihood ratio of a positive test, $L R$ likelihood ratio of a negative test

with premenopausal bleeding. Several previous studies have evaluated the role of 3D ultrasonography/power Doppler for the investigation of patients with postmenopausal bleeding.

Our results showed that the ET, EV, and endometrial VI and VFI were significantly increased in patients with malignant endometrium than those with benign endometrium; whereas, the uterine artery PI and RI and endometrial FI were not significantly different between the two groups. The best parameter for discrimination between benign and malignant endometrium was the VI with an AUC of 0.88 at a cutoff value of $0.81 \%$.

In agreement with our results, Mercé et al. [9] and Alcazar and Galvan [10] found that the flow indices were superior to EV for discrimination between endometrial carcinoma and endometrial hyperplasia, and between benign and malignant endometrium, respectively. The best predictor for endometrial cancer was VI. Odeh et al. [11], however, found that EV was superior to the flow indices for discrimination between hyperplasia/malignant endometrium and benign endometrium other than hyperplasia.

Epstein et al. [12] estimated the color content of the endometrium subjectively by choosing the most vascularized area and applying computer analysis to that area. They concluded that power Doppler analysis can contribute to a correct diagnosis of endometrial cancer in women with postmenopausal bleeding. Makled et al. [13] also concluded that $3 \mathrm{D}$ power Doppler measurements may be useful for distinguishing between benign endometrial lesions and endometrial carcinoma in women with postmenopausal bleeding.

Kurjak et al. [14] and Kupesic et al. [15] reported the use of volume measurements and power Doppler in diagnosing endometrial and adnexal malignancies; they found significant differences in the volume of malignant and benign lesions. They suggested that a combination of morphologic criteria and $3 \mathrm{D}$ power Doppler findings could identify endometrial lesions with sensitivity and specificity of 89 and $97 \%$, respectively.

Galván et al. [16] found that EV and VI were independently related to myometrial infiltration and tumor stage in endometrial carcinoma; VI was independently associated with tumor grade and EV correlated with lymph node metastases. Saarelainen et al. [17] also suggested that endometrial and, to a lesser degree, myometrial vascular indices and EV correlate with the depth of myometrial invasion in endometrial carcinoma.

Contrary to our results, Lieng et al. [18] did not find differences in 3D power Doppler indices between women with endometrial polyps and endometrial cancer before and after contrast enhanced examination. Opolskiene et al. [19] also concluded that, although 3D power Doppler indices were significantly higher in women with endometrial cancer as compared with those with benign pathology, the diagnostic performance of $3 \mathrm{D}$ ultrasound imaging was not superior to that of ET as measured by $2 \mathrm{D}$ ultrasound examination.

De Smet et al. [20] analyzed the correlation between EV and myometrial infiltration in a series of 97 women with endometrial cancer. They found that the predicted probability of deep myometrial infiltration increased when the ET increased, while this probability decreased when EV increased. This could be explained by non-linear effects.

The differences in results between our study and previous studies can almost certainly be explained by substantial differences in study populations and study design. There are differences in menopausal status, use of hormone replacement therapy, rate of endometrial cancer, and mix of benign histologies. There are also differences in the methods used to determine diagnostic performance of ultrasound markers. The relatively high rate of endometrial carcinoma and atypical hyperplasia in our study can be explained by exclusion of other causes of premenopausal bleeding in the study population.

\section{Conclusions}

Three-dimensional ultrasonography and power Doppler, especially endometrial VI, may be useful for discrimination between benign and malignant endometrium in premenopausal women with abnormal uterine bleeding before resorting to invasive procedures such as hysteroscopy and endometrial curettage. However, due to our relatively small sample size, further studies in larger series are needed to confirm these data.

\section{Competing interests}

The authors declare that they have no competing interests.

\section{Authors' contribution}

MES contributed in study design and manuscript drafting and revising. AEM contributed in study design and statistical analysis. WR contributed in data interpretation and manuscript drafting. DH contributed in study design and manuscript revising. AAH contributed in data interpretation and manuscript 
drafting. $\mathrm{MH}$ contributed in data interpretation and manuscript revising. AN contributed in data interpretation and manuscript revising. All authors read and approved the final manuscript.

\section{Acknowledgement}

None

\section{Funding}

None

Received: 6 January 2015 Accepted: 9 March 2016

Published online: 16 March 2016

\section{References}

1. Parkin DM, Bray F, Ferlay J, Pisani P. Global cancer statistics, 2002. CA Cancer J Clin. 2005:55(2):74-108

2. Sorosky Jl. Endometrial cancer. Obstet Gynecol. 2008;111(2 Pt 1):436-47.

3. Mettler L. The cystic adnexal mass: patient selection, surgical techniques and long-term follow-up. Curr Opin Obstet Gynecol. 2001; 13(4):389-97.

4. Clark TJ, Barton PM, Coomarasamy A, Gupta JK, Khan KS. Investigating postmenopausal bleeding for endometrial cancer: cost-effectiveness of initial diagnostic strategies. BJOG. 2006;113(5):502-10.

5. Dijkhuizen FP, Mol BW, Brölmann HA, Heintz AP. Cost-effectiveness of the use of transvaginal sonography in the evaluation of postmenopausal bleeding. Maturitas. 2003;45(4):275-82.

6. Bega G, Lev-Toaff AS, O'Kane P, Becker Jr E, Kurtz AB. Three-dimensional ultrasonography in gynecology: technical aspects and clinical applications. J Ultrasound Med. 2003;22(11):1249-69.

7. Alcázar JL, Jurado M. Three-dimensional ultrasound for assessing women with gynecological cancer: a systematic review. Gynecol Oncol. 2011;120(3): 340-6.

8. Campbell S. Placental vasculature as visualized by 3D power Doppler angiography and 3D color Doppler imaging. Ultrasound Obstet Gynecol. 2007; 30(6):917-20.

9. Mercé LT, Alcázar JL, Engels V, Troyano J, Bau S, Bajo JM. Endometrial volume and vascularity measurements by transvaginal three-dimensional ultrasonography and power Doppler angiography in stimulated and tumoral endometria: intraobserver reproducibility. Gynecol Oncol. 2006; 100(3):544-50.

10. Alcazar JL, Galvan R. Three-dimensional power Doppler ultrasound scanning for the prediction of endometrial cancer in women with postmenopausal bleeding and thickened endometrium. Am J Obstet Gynecol. 2009;200(1):44. e1-6.

11. Odeh M, Vainerovsky I, Grinin V, Kais M, Ophir E, Bornstein J. Threedimensional endometrial volume and 3-dimensional power Doppler analysis in predicting endometrial carcinoma and hyperplasia. Gynecol Oncol. 2007:106(2):348-53.

12. Epstein E, Skoog L, Isberg PE, De Smet F, De Moor B, Olofsson PA, Gudmundsson $S$, Valentin L. An algorithm including results of gray-scale and power Doppler ultrasound examination to predict endometrial malignancy in women with postmenopausal bleeding. Ultrasound Obstet Gynecol. 2002;20(4):370-6.

13. Makled AK, Elmekkawi SF, El-Refaie TA, El-Sherbiny MA. Three-dimensional power Doppler and endometrial volume as predictors of malignancy in patients with postmenopausal bleeding. J Obstet Gynaecol Res. 2013;39(5):1045-51.

14. Kurjak A, Kupesic S, Sparac V, Bekavac I. Preoperative evaluation of pelvic tumors by Doppler and three-dimensional sonography. J Ultrasound Med. 2001;20(8):829-40.

15. Kupesic S, Kurjak A, Hajder E. Ultrasonic assessment of the postmenopausal uterus. Maturitas. 2002;41(4):255-67.

16. Galván R, Mercé L, Jurado M, Mínguez JA, López-García G, Alcázar JL. Threedimensional power Doppler angiography in endometrial cancer: correlation with tumor characteristics. Ultrasound Obstet Gynecol. 2010;35(6):723-9.

17. Saarelainen SK, Vuento MH, Kirkinen P, Mäenpää JU. Preoperative assessment of endometrial carcinoma by three-dimensional power Doppler angiography. Ultrasound Obstet Gynecol. 2012;39(4):466-72.
18. Lieng M, Qvigstad E, Dahl GF, Istre O. Flow differences between endometrial polyps and cancer: a prospective study using intravenous contrast-enhanced transvaginal color flow Doppler and threedimensional power Doppler ultrasound. Ultrasound Obstet Gynecol. 2008;32(7):935-40

19. Opolskiene G, Sladkevicius $P$, Jokubkiene L, Valentin L. Three-dimensional ultrasound imaging for discrimination between benign and malignant endometrium in women with postmenopausal bleeding and sonographic endometrial thickness of at least 4.5 mm. Ultrasound Obstet Gynecol. 2010; 35(1):94-102.

20. De Smet F, De Brabanter J, Van den Bosch T, Pochet N, Amant F, Van Holsbeke C, Moerman P, De Moor B, Vergote I, Timmerman D. New models to predict depth of infiltration in endometrial carcinoma based on transvaginal sonography. Ultrasound Obstet Gynecol. 2006;27(6):664-71.

\section{Submit your next manuscript to BioMed Central and we will help you at every step:}

- We accept pre-submission inquiries

- Our selector tool helps you to find the most relevant journal

- We provide round the clock customer support

- Convenient online submission

- Thorough peer review

- Inclusion in PubMed and all major indexing services

- Maximum visibility for your research

Submit your manuscript at www.biomedcentral.com/submit 